\title{
Los derechos sociales como derechos subjetivos fundamentales
}

\section{The Social Rights as Subjective Fundamental Rights}

\author{
Álvaro Echeverri Uruburu *
}

Fecha de recepción: 7 de julio de 2008

Fecha de aprobación: 18 de septiembre de 2008

\begin{abstract}
La experiencia sugiere que siempre habrá un sesgo sistemático en la opción judicial de los valores fundamentales, como es de esperarse, a favor de los valores de la clase media alta profesional de la que proviene la mayor parte de los abogados, jueces y, dicho sea de peso, de los filósofos morales. Es comprensible que se piense que aquello que se considera importante es lo importante [...] Así, la lista de valores que la Corte y los comentaristas han tendido a consagrar como fundamentales es una lista que los lectores no tendrían dificultad en identificar: expresión, asociación, educación, libertad académica, privacidad del hogar, autonomía personal, incluso el derecho a no ser encerrado en un papel estereotipado femenino [...]. Pero hay que ver a los teóricos de los derechos fundamentales dirigirse a la puerta apenas se mencionan el empleo, la alimentación o la vivienda: éstos son importantes, ciertamente, pero no son Fundamentales
\end{abstract}

(Hart Ely, 1997, p. 80).

\section{Resumen}

El texto tiene como objetivo analizar cuáles son los derechos fundamentales y si los derechos sociales hacen parte de esta categoría. Para ello se recurre al análisis desde una perspectiva histórica, tomando como enfoque la teoría constitucional. A nivel metodológico el texto se apoya en una variada y solida fuente bibliográfica de autores nacionales y extranjeros.

\footnotetext{
* Miembro en la Asamblea Nacional Constituyente de 1991 que expidió la actual Carta Política de Colombia. Profesor y actualmente Decano de la Facultad de Derecho de la Universidad Santo Tomás de Bogotá. Autor, entre otras obras: Teoría Constitucional y Ciencia Política (6a edición, 2002). Correo electrónico: alvaroecheverri@correo.usta.edu.co
} 


\title{
Palabras clave
}

Derechos fundamentales, derechos sociales, exigibilidad, corte interamericana.

\begin{abstract}
This text has the objective to analyze which are the fundamental rights and if the social rights make part of this category. For this there's an analysis from the historic perspective, taking as an approach the constitutional theory. At a methodological level the text is supported in a varied and solid bibliographic source with national and foreign authors.
\end{abstract}

\section{Key words}

Fundamental rights, social rights, demandability, interamerican court.

\section{INTRODUCCIÓN}

Las expresiones anteriores de Ely que encabezan este artículo, quizá debieron estar al final de éste como su síntesis conclusiva. La obra de Ely, calificada por muchos como la más importante del Constitucionalismo Norteamericano durante los últimos años, devela con gran sentido común y mucho humor, los prejuicios ideológicos que subyacen en los grandes problemas de la Teoría Constitucional Contemporánea, como el tema que nos ocupa, esto es, saber cuáles deben ser los derechos fundamentales y si los derechos sociales caben dentro de esta categoría.

Casi desde la introducción de estos Derechos por primera vez en una Constitución democrática como la de Weimar de 1919, si se recuerdan las expresiones de Karl Schmitt con respecto a que los derechos sociales, no cabían más que en el Estado Socialista totalitario; se ha discutido sobre si aquéllos son verdaderos derechos y si pueden alcanzar la categoría de fundamentales.

El carácter supuestamente indeterminado de los sujetos titulares de los derechos sociales, de las prestaciones a los que tendrían derecho y del sujeto pasivo de las obligaciones, comportaría el escaso margen de exigibilidad de tales derechos. Como se sabe, la exigibilidad, particularmente judicial, es como lo afirma Kelsén (1953): "el elemento constitutivo de los derechos subjetivos".

Por su parte, Ernst Wolfgang Bockenförde, ex-juez del Tribunal Constitucional Alemán, sostiene que la diferencia entre los derechos de libertad y los derechos sociales es determinante a la hora de definir su exigibilidad. A su juicio, los derechos de libertad son protegibles judicialmente, porque el bien objeto de la protección está dado de manera "natural" y previa. Al juez sólo le corresponde reconocer lo que ya está allí y protegerlo de intromisiones estatales. Por el contrario, cuando se trata de los derechos sociales, "la pretensión contenida en ellos es tan general, que no pueden extraerse de ellos pretensiones jurídicas concretas por vía de la interpretación" (Citado por Arango, junio de 2001, p. 187).

En el curso de este artículo, desde un punto de vista contrario a las posiciones antecedentes, se analizarán: la naturaleza jurídica, como derechos subjetivos de los derechos sociales; su categorización como derechos fundamentales y los problemas de exigibilidad; y los sistemas internacionales de protección de los derechos sociales, que a mi juicio, han zanjado las diferencias conceptuales. 


\section{LOS DERECHOS SOCIALES COMO DERECHOS SUBJETIVOS}

Independientemente del carácter conflictivo del concepto de derecho subjetivos ${ }^{1}$, incluso desde sus orígenes, es evidente que éste posee una existencia innegable en el discurso jurídico (doctrinal y jurisprudencial), lo mismo que en las distintas practicas jurídicas.

El profesor Hartmut Maurer, define el concepto de derecho subjetivo así:

Es el poder legal reconocido a un sujeto por medio de una norma jurídica para la persecución de sus intereses propios mediante la exigencia a otros de hacer, permitir u omitir algo.

Por lo tanto, los elementos del derecho subjetivo son:

- Una norma jurídica;

- Una obligación jurídica, que corresponde a otro con fundamento en esa norma;

- Un poder jurídico, reconocido por la norma al sujeto para la consecución de intereses propios.

Desde una perspectiva realista (a la que responde el concepto de Maurer), Von Ihering situó la base del derecho subjetivo en un interés, digno de ser tutelado por la norma. "Los derechos, podrá escribir, no existen para realizar la voluntad en abstracto, sino para asegurar intereses en la vida, entendiendo por interés, todo lo que puede mover al ser humano" (Diccionario Jurídico Espasa y Calpe, 1998, p. 330). Pero la concepción de Ihering se mueve en el contexto ideológico del indivi-

1 "[...] desde el punto de vista de una descripción científica exacta, dicho concepto es superfluo" (Kelsén, s.f.). "[...] no es una modalidad usada en la formación de una regla jurídica particular, sino más bien una construcción teórica que sirve a la presentación sistemática del derecho vigente "(Alf Ross) y más adelante agrega Ross: "[...] El concepto de derecho subjetivo no tiene referencia semántica alguna. No designa fenómeno alguno de ningún tipo" (Citado por Arango, 2005, p. 7). dualismo que inspiró las revoluciones burguesas de los siglos XVII y XVIII e influyó en las primeras codificaciones del siglo XIX.

Modernamente, la importancia de las concepciones sociales triunfantes en amplios sectores del mundo [...] ha destacado más que la importancia de una concepción jurídica radicalmente individualista, la necesidad de armonizar las exigencias del reconocimiento de una esfera de poder propia del individuo (Diccionario Jurídico Espasa y Calpe, 1998).

Lo anterior, se encuentra conjuntamente con otros valores y exigencias de grupos y sectores de la sociedad subordinadas o en circunstancias de exclusión de los bienes producidos por la civilización moderna. Por eso, tal como lo recuerda el Profesor Rodolfo Arango (2005), H. Hart invitaba a proseguir el análisis del concepto de derecho subjetivo, como se utiliza en el discurso jurídico, "sobre una base ampliada". A continuación justificaba su propuesta, al señalar su necesidad para

[...]acomodarse al importante desarrollo
del lenguaje jurídico por parte de los cons-
titucionalistas y de la crítica individualista
de la Ley, para quienes el centro de la no-
ción de derechos no es la elección indivi-
dual, ni el beneficio individual, sino las ne-
cesidades básicas o fundamentales de la
persona (la cursiva es mía) (Arango, 2005).

Como lo ha señalado Carlos Bernal Pulido, la idea de unos individuos autónomos y autosuficientes, capaces de valerse por sí mismos, propia de las concepciones burguesas del individuo, da origen a una concepción abstentiva de los derechos que tan sólo demanda protección de las amenazas externas. Este idealismo choca con la realidad de grandes sectores y grupos de la sociedad que "no pueden valerse por sí mismos". Así, del concepto de autonomía de la voluntad para actuar (Savigny) o del interés individual (Von Ihering), como fundamentos de los derechos subjetivos, o más exactamente, para responder a la pregunta de qué derechos debe tener una persona, se ha arribado al concepto de necesidad. 
El concepto de necesidad parte de la realidad acerca de la existencia de sectores o grupos numerosos de la sociedad que carecen de los bienes indispensables para subsistir y poder ejercer los demás derechos. La característica de esta carencia es que los individuos que conforman dichos grupos o sectores se encuentran en imposibilidad de acceder a dichos bienes por distintas causas (insuficiencias físicas, psicológicas o estructurales, como por ejemplo, crisis económicas o el lento desarrollo productivo de la sociedad). En tales circunstancias, debe operar el principio de solidaridad $_{\iota}$ que obliga a los demás miembros de la sociedad, organizados en el Estado, a procurarles dichos bienes. En este contexto -como lo ha señalado Bernal Pulido, citando a M. Borgetto-, "el principio de solidaridad constituye un deber de ayuda mutua", un verdadero principio de acción política inscrito en la noción de 'Fraternité' del Revolucionarismo Francés" (citado por Bernal, 2005, p. 297).

La ayuda que se demanda primeramente del Estado para los individuos y grupos de la sociedad carentes de los bienes indispensables para su subsistencia, debe respetar, con todo, su autonomía y libertad, de suerte que se les proporcionen los medios para que ellos se ayuden a sí mismos.

A este criterio obedece el Art. 13 de la Constitución Política de Colombia, cuando señala: "El Estado promoverá las condiciones para que la igualdad sea real y efectiva y adoptarálas medidas a favor de grupos discriminados y marginados" (las cursivas son mías). En este sentido, los derechos sociales valen por sí mismos y no como condiciones de posibilidad para el ejercicio de otros derechos, particularmente los civiles y políticas, que ha sido la justificación tradicional de los derechos sociales²,

2 Así, por ejemplo, Herman Heller planteaba la "democracia económica", a partir de los derechos sociales y económicos, como el fundamento de la "democracia política". Alexy fundamenta los derechos sociales en el principio de libertad, seguido en este aspecto por Böckenforde, para quien los derechos sociales constituyen un "principio de aseguramiento de la libertad" (citado por Bernal 2005, p. 298). Por su parte, la comisión Interamericana de Derechos Humanos ha destacado: "La estrecha relación que prácticamente desde Weimar, respondiendo a las críticas de Marx sobre el carácter ficticio e irreal de los derechos liberales.

Independientemente de que se acepte que sin una base material de satisfacción de las necesidades esenciales para la subsistencia del ser humano no es posible el goce y el ejercicio de otros derechos, lo que los teóricos Ilaman la integralidad, indisubilidad e interdependencia de los derechos, lo que en verdad importa es el reconocimiento que el hombre tiene ciertas necesidades", que "le son inherentes", es decir, que dimanan de su dignidad humana "y cuya satisfacción es uno de los fines de la comunidad política. Dichas necesidades fundamentan los derechos sociales" (las cursivas son mías) (Bernal, 2005, p. 300).

El profesor Rodolfo Arango, en una obra que ya se ha convertido en un clásico de la literatura jurídica colombiana, propone la fundamentación de los derechos sociales como derechos subjetivos, desde una perspectiva eminentemente lógica. El profesor Arango sostiene que la posición jurídica del individuo, que la norma le reconoce y protege, merece tal reconocimiento y protección porque puede ser justificada mediante buenas razones.

existe entre la vigencia de los derechos económicos, sociales y culturales y la de los derechos civiles y políticos, por cuanto las diferentes categorías de derechos constituyen un todo indisoluble que encuentra su base en el reconocimiento de la dignidad de la persona humana [...] sin que jamás se justifique la violación de un derecho en aras de la realización de otros" (Fajardo, juliodiciembre de 2005).

3 El hecho elemental de que el hombre tenga necesidades básicas para su subsistencia ya había sido señalado por Santo Tomás, cuando en el siglo XIII afirmaba que el hombre antes de pensar en su salvación eterna, primero tenía que pensar en comer, cómo vestirse y tener un techo para alojarse. En este sentido, el profesor Joaquín Herrera ha señalado cómo se ha debilitado la idea de que los seres humanos necesitamos el acceso a bienes básicos para la existencia. "Ese supuesto ha hecho surgir una actitud vergonzante sobre las necesidades, que se transmite en cierta forma a la concepción de la dignidad. Por esto, el discurso sobre la dignidad humana tiende a ser abstracto y sin referencias a la materialidad de la existencia humana. Es imprescindible, por lo mismo, rescatar los valores mundanos o terrenales de los derechos humanos y de la dignidad, asociándolos sin prejuicios al acceso a bienes y recursos indispensables para la existencia material" (Herreño, 2008, p. 111). 
Esto es, que la posición jurídica que comportan los derechos subjetivos tiene que ser construida discursivamente. Por lo tanto, no es un dato dado de una vez y para siempre, como lo creía la noción iusnaturalista de los derechos y a la cual respondían las primeras conceptualizaciones de los derechos subjetivos.

La posición jurídica de un sujeto, reconocida por el ordenamiento "debe entenderse como: 1) lo que puede ser fundamentado con razones válidas y suficientes y II) la que de su no reconocimiento injustificado se ocasiona un daño inminente al sujeto".

Como ya se dijo, el punto I) es un construcción discursiva, esto es, que se alcanza con la ayuda de la argumentación jurídica, de suerte tal, que los "derechos son antes que nada exigencias justificadas". El punto II) constituye el detrimento "individual directo" del que hablaba Bentham como justificación genérica de los derechos.

Ahora bien, con respecto a los derechos sociales como derechos subjetivos, es posible aplicar los criterios I), razones fundadas para su reconocimiento, acudiendo a la argumentación basada en el principio de necesidad o al más tradicional del carácter interdependiente de todos los derechos. Lo mismo con el II), el daño individual inminente para el caso de su no reconocimiento injustificado. En este punto, es necesario resaltar que el daño no sólo puede provenir de actos positivos, sino también de omisiones. Arango concluye sobre este aspecto: "La urgencia de una situación en la clave para la resolución del problema de la indeterminación" de los derechos sociales (2005, p. 145).

Para saber cuándo en una situación concreta una omisión en la prestación es condición suficiente para la producción de un daño individual inminente, es necesario imaginarse qué podría pasar de no acceder a la prestación que permitiría satisfacer la necesidad básica. Por lo tanto, se trata de una argumentación empírica que introduce el juego de contrafácticos para establecer un derecho.

Robert Alexy sostiene que los Derechos Humanos, incluidos los sociales, son derechos subjetivos que se diferencian de otras categorías de derechos por cinco características:

- Universalidad: su titularidad radica en todo ser humano y sus obligados son todas las personas y organizaciones.

- Validez moral: una norma tiene validez moral "cuando ella puede ser justificada ante cualquier persona que esté dispuesta a tomar parte en el discurso de fundamentación racional".

- Fundamentalidad: tiene que ver con la satisfacción de intereses y necesidades básicas, así como con su debida protección.

- Prioridad: como condición de legitimidad del derecho positivo y del Derecho en general.

- Abstracción: se relaciona con la indeterminación de la estructura de estos derechos en cuanto a sus titulares, objeto y límites. Con todo, las definiciones constitucionales, los pactos, tratados y convenios sobre estos derechos han buscado reducir su indeterminación (Arango, noviembre de 1999, pp. 252 y ss.; Alexy, 1997, pp. 173 y ss.).

\section{TRANSFORMACIÓN DE LOS DERECHOS SOCIALES SUBJETIVOS EN DERECHOS FUNDAMENTALES}

\section{Los Derechos Sociales como Derechos Humanos positivizados constitucionalmente}

A nuestro juicio, basta, que los derechos sociales se encuentran consagrados en la Constitución para considerarlos como derechos fundamentales. Por supuesto, a esta posición no responde la categorización que de estos derechos hacen tanto la Ley Fundamental Alemana (Art. 1 al Art. 19) como la 
Constitución Española (capítulos primero y segundo, Art. 10 al 38).

Esta parcelación de los derechos, en la cual unos (Ios derechos civiles y políticos), al ser definidos como fundamentales, parecerían más importantes que otros; no obstante, éstos igualmente están inscritos en la Constitución, parece cada vez más menos plausible desde la perspectiva de la dignidad humana, justificación última y necesaria de los derechos fundamentales. Al respecto, el reconocido constitucionalista argentino, Germán Bidart Campos, sostiene:

\begin{abstract}
La visión actualmente pesimista o negativa (en cuanto a la vigencia de los derechos sociales) nos incita, como a cuantos desde el ámbito académico se ocupan del tema, a bregar por el Estado Social y democrático de derecho, en el cual resulta inadmisible_incomunicar los derechos económicos, sociales y culturales, de los clásicos derechos civiles y políticos, por aquello tan repetido, pero muchas veces olvidado y vilipendiado de la indivisibilidad de los derechos humanos, cualquiera sea la categoría, el tipo, la generación o el rotulo con que se haga mención de ellos (la cursiva es mía) (Bidart, 1996, p. 119).
\end{abstract}

No sobra anotar que este debate no es puramente académico, pues tiene enorme incidencia en el campo de la exigibilidad de los derechos, gracias al "Plus" de garantía que les confiere su fundamentalidad, por cuanto todo derecho fundamental es justiciable, "prima facie", de forma inmediata.

Así, la Corte Constitucional colombiana define, en general, los derechos fundamentales como derechos subjetivos de aplicación inmediata, que se reconocen -directa o indirectamente- en el texto constitucional. "De allí se deduce que tienen prevalencia sobre otros derechos o garantías legales y no están sometidos a las decisiones eventuales de las mayorías políticas" (Herreño, 2008, p. 184) en el Congreso.
De acuerdo con esto, la Corte Constitucional ha mantenido una clara línea jurisprudencial que incluye entre los derechos fundamentales aquellas prestaciones de tipo social, relacionadas directamente con la dignidad humana, como por ejemplo, la educación básica, el pago oportuno de las mesadas pensionales o del salario mínimo, los servicios básicos de salud, etc. Algunas de estas prestaciones se recogen en el concepto genérico de "mínimo vital" o "mínimo existencial" (Herreño, 2008).

El argumento lógico para defender la fundamentalidad de los derechos sociales es, desde luego, que ellos son necesarios para garantizar plenamente la dignidad de la persona humana en un Estado Social de Derecho, por lo que ellos deben ser positivizados constitucionalmente como derechos subjetivos fundamentales, esto es, como "necesidades humanas socialmente objetivadas" (Barcesat, 2004) merecedoras de protección (Herreño, 2008, p. 121).

Ahora bien, la posición de la Corte Constitucional colombiana al ampliar la comprensión y el campo de aplicación de los derechos fundamentales a los derechos sociales se demuestra que más allá de las razones suficientes para el reconocimiento o no de unos derechos (argumentación jurídica al estilo de Rodolfo Arango o de su maestro, Robert Alexy), el problema corresponde más a consideraciones de filosofía política y a decisiones políticas concretas. Como lo reconoce Rodolfo Arango, en las sociedades desarrolladas que él denomina -siguiendo a Rawls- "bien ordenadas":

[...] la satisfacción de las necesidades básicas de la población está legalmente asegurada. En estas circunstancias, puede nacer un sentimiento de justicia en cada persona. En este tipo de sociedades, la conciencia de la importancia de los derechos humanos sociales es reducida, en gran parte porque se tienen como algo sobrentendido [...] tratándose de sociedades no bien ordenadas, las cosas son a otro precio. Porque las instituciones 
adecuadas para el aseguramiento de las necesidades básicas de los miembros de la comunidad no están consolidadas, los derechos humanos sociales adquieren elevada importancia, tanta o más, que la atribuida a los derechos de libertad clásica (Arango, 1999, p. 159).

En este tipo de sociedades:

[...] la justicia constitucional maniobra en contra de las omisiones estatales en el cumplimiento de sus fines, de forma que el déficit de participación democrática es compensado con la constitucionalización de amplios ámbitos del derecho y de la vida social en general. En esto se muestra que los temores de una transición hacia un Estado judicial (Bockenförde, 1992) no son teóricos, sino reales. Estas son, sin embargo, las consecuencias indeseables de la disfuncionalidad estatal, mas no del principio de inmunidad de los derechos fundamentales. Una Corte Constitucional no puede ser en un Estado Social de Derecho, una convidada de piedra frente a la inacción legislativa (Arango, 1999, p. 161).

\section{Estructura jurídica y exigibilidad de los derechos sociales}

Para muchos autores, la diferencia radical entre los derechos de libertad (derechos civiles y políticos) y los derechos sociales está dada por el carácter indeterminado de las obligaciones que se desprenden de estos derechos, así como del sujeto pasivo de estas obligaciones, dado que en muchos casos el Estado sólo aparece como obligado subsidiario.

En primer lugar, cabe observar que ésta es solamente una diferencia de grado, pues, en general, todos los derechos sufren de esta "indeterminación normativa", sólo que en los derechos sociales los medios para su satisfacción pueden ser muy variados, de ahí que en las prescripciones constitucionales resulte más difícil precisarlas integralmente, lo que no ocurre con los derechos civiles y políticos, en los que resulta relativamente fácil señalar los medios para su protección -a través de prohibiciones o prestaciones dirigidas al Estado o a los particulares.
Ahora bien, del hecho de que los derechos sociales están sometidos a la "libertad de configuración" que posee el legislador democrático para escoger los medios, el quantum de satisfacción y el momento en que tales medios deben ser adoptados - de acuerdo con las disponibilidades presupuestales o con los problemas de la coyuntura económica-; de este hecho, se repite, no se puede deducir que los derechos sociales carezcan de naturaleza jurídica y se les trate como simples aspiraciones y horizontes apenas de prescripciones programáticas para el Estado, por cuanto dichos derechos están dispuestos en la Constitución con un sentido no puramente simbólico de atracción de legitimidad, sino con vocación de realización efectiva, como ocurre, además, con el resto del entramado, normativo constitucional. Pues -como sostiene Bernal Pulido-: "la necesidad de que el legislador disponga de un amplio margen de acción, no despoja a los derechos sociales de toda fuerza vinculante", como lo pretende la tesis que considera dichos derechos como simples normas programáticas, "así como la vinculación que emana de estos derechos no puede, tampoco, expropiar absolutamente al parlamento de su libertad de decisión" (Bernal, 2005, p. 307).

La estructura jurídica de los derechos sociales corresponde a dos tipos de prescripciones, a saber: la proclamación del derecho, en general, y la determinación del título (generalmente la ley) a partir del que se define el marco prestacional. La proclamación del derecho no requiere de ningún título distinto a su incorporación constitucional, de ahí su carácter categórico. Por lo tanto, se trata de definiciones abstractas que sólo se dejan precisar en una situación fáctica concreta. En el segundo caso, la ley proporciona el título adquisitivo del derecho.

De esta estructura dual de las normas que contienen derechos sociales, se desprenden dos formas de exigibilidad de estos derechos: la protección individual de los derechos sociales, y la exigibilidad 
de políticas públicas para la realización de este tipo de derechos.

\section{La protección individual de los derechos sociales}

Esta protección se da cuando obligatoriamente debe concurrir el Estado para su prestación, se puede formular axiomáticamente así: el Estado está obligado a una prestación positiva a favor de una persona, cuando se cumplen precisas condiciones extra-normativas. Dichas condiciones tienen que ver con situaciones de necesidad extrema de la persona, cuya superación exige jurídicamente una intervención estatal para evitar un daño inminente para aquélla (Arango, 1999, p. 189) .

La Corte Constitucional colombiana ha construido el concepto de exigibilidad particular de un derecho social, atendiendo a estos criterios:

- El Estado, a través del legislativo, tiene la competencia para determinar prestaciones públicas a favor de las personas (distribución democrática de los recursos de la sociedad).

- Los derechos sociales (salud, educación, alimentación, vivienda, etc.), en principio, no son exigibles del Estado de forma individual.

- Cuando la persona (y su familia) se encuentran:

- En situación de necesidad que amenaza gravemente sus derechos fundamentales (principio de conexidad de un derecho social con un derecho reconocido expresamente como fundamental).

- Cuando el legislador no ha tomado las medidas requeridas para enfrentar esta situación;

- La actuación positiva del Estado puede evitar el perjuicio a los derechos fundamentales de la persona;

- De no producirse la intervención del Estado dicho perjuicio necesariamente se materia- lizaría. En tales condiciones, cabe pues, la exigibilidad de la prestación que el Estado debe realizar o garantizar frente a terceros.

El "argumento de oro" de esta construcción jurisprudencial radica en que una grave omisión del legislador o de la administración no puede tener más fuerza que el principio de inmunidad de los derechos fundamentales, máxime si se atiende al Estado Social de Derecho que fue la forma de Estado que el constituyente colombiano consideró como la más adecuada para enfrentar la situación de pobreza extrema, desigualdad y confrontación armada que vive el país.

\section{La exigibilidad de políticas públicas}

En la mayoría de las constituciones contemporáneas que incorporan expresos derechos sociales, la enumeración de estos corresponde a lo que Carlos Bernal Pulido denomina -siguiendo a Luhamnn"normas de programación final" (2005, p. 307), en las cuales el mandato para el Estado, en caso de que éste sea el obligado a la prestación, es un "mandato de optimación", mediante el cual se señala el objetivo que debe ser alcanzado; por ejemplo, "toda persona tiene derecho a la salud"; "toda persona tiene derecho a una vivienda digna"; "toda persona tiene derecho a la educación hasta el grado $9^{\circ}$ ", etc., pero no se señalan los medios para conseguirlo ${ }^{4}$.

El caso colombiano en materia de consagración de derechos sociales es algo diferente. Si se recoge la experiencia nacional de la inefectividad de las reformas sociales, particularmente de las grandes transformaciones realizadas a la anterior constitución de 1886 durante la llamada "Revolución en marcha" de 1936 y que permanecieron como "promesas incumplidas" por más de cincuenta años, el constituyente del 91 quiso que, al tiempo que se consagraba el

4 Por tal razón Ignacio De Otto, señala que de ordinario las disposiciones sobre derechos sociales sólo especifican el fin, sin hacer alusión a los medios para alcanzarlo. 
respectivo derecho social, se le señalaran al Estado las medidas concretas que éste debía adoptar para su efectividad y cumplimiento. Por ejemplo, el Art.67 de la Constitución consagra el derecho a la educación como "un derecho de la persona y un servicio público que tiene una función social". A continuación fija el marco de las políticas públicas en esta materia, al señalar que la educación:

\section{[...] será obligatoria entre los cinco y quince años de edad y comprende- rá como mínimo, un año de prees- colar y nueve de educación básica. \\ [...] La educación será gratuita en las instituciones del Estado, sin perjui- cios del cobro de derechos académi- cos a quienes puedan sufragarlos. \\ [...] la Nación y las entidades terri- toriales participarán en la direc- ción, financiación y administración de los servicios educativos estatales.}

El Art. 48 define el derecho a la seguridad social, así: "se garantiza a todos los habitantes el derecho irrenunciable, a la seguridad social. A continuación señala los medios de efectivización así: "El Estado, con la participación de los particulares, ampliará progresivamente la cobertura en la seguridad social [...] la ley definirá los medios para que los recursos destinados a pensiones mantengan un poder adquisitivo constante".

El Art. 51, al consagrar de manera general el derecho social a la vivienda, expresa: "todos los colombianos tiene derecho a vivienda digna". Señala a continuación las políticas públicas que el Estado debe cumplir para la realización de este derecho: "El Estado fijará las condiciones necesarias para hacer efectivo, este derecho y promoverá planes de vivienda de interés social, sistemas adecuados de financiación a largo plazo y formas asociativas de ejecución de estos programas".

Al establecer el derecho a la seguridad alimentaria, "el derecho a no tener hambre" en la conceptualización de Amartya Sen, el Art. 65 señala:
La producción de alimentos gozará de la especial protección del Estado. Para tal efecto, se otorgará prioridad al desarrollo integral de las actividades agrícolas, pecuniarias, pesqueras, forestales $y$ agroindustriales, así como también a la construcción de obras de infraestructura física y adecuación de tierras.

[...] De igual manera, el Estado promoverá la investigación y la transferencia de tecnología para la producción de alimentos y materias primas de origen agropecuario con el propósito de incrementar la productividad.

Basta señalar estos pocos artículos, que constituyen el núcleo duro de los derechos sociales, en el caso de la constitución colombiana. Por su parte, el Estado no sólo está vinculado en cuanto a los fines previstos para aquellos derechos, sino también en cuanto a los medios que debe adoptar para su efectiva realización. Medios, que cabe aclararlo, no son taxativos ni excluyentes con respecto a otros, igualmente posibles y adecuados para la consecución de los fines normativos. Desde esta perspectiva, la Constitución del 91 busca salvar el obstáculo de la indeterminación de los medios para la realización de los derechos sociales, vinculando al Estado, en sus ramas legislativa y ejecutiva, para la adopción y ejecución de medidas legislativas y políticas publicas que sirvan a este objetivo.

Con todo, lo anterior no impide, como lo han demostrado los más de quince años de vigencia de la Constitución actual de Colombia, la inacción y la "desatención grosera" a los fines del Estado social, demostrada durante este tiempo, tanto por el ejecutivo como por el legislativo, en estas materias.

Böckenforde buscó precisar los aspectos centrales de la vinculación del legislador en las medidas que debe adoptar para la realización de los derechos sociales, en virtud de su indeterminación -que reitero no es exactamente el caso colombianoseñaló tres criterios: 
- La prohibición absoluta de la inactividad del legislador para la adopción de los medios idóneos para la realización de los fines previstos en las normas sociales de la Constitución. Con esto enfrenta una visión puramente programática de estos derechos, para la cual no existe tal obligación de actuación del legislador y, por consiguiente, los fines que ellos persiguen se difieren a un futuro incierto y a una protección sine die, como lo denunciara Norberto Bobbio (1991).

- La prohibición de establecer medios inidóneos para la consecución de los fines previstos en las normas sociales.

- Medios inidóneos son aquéllos que demuestran -según Böckenforde- una "desatención evidente y grosera" de esos fines. Es lo que la doctrina alemana llama "protección deficiente" de los derechos.

- La prohibición de la adopción de medidas que impliquen un retroceso con respecto a las normas ya vigentes para el cumplimiento esos fines ${ }^{5}$.

Ahora bien, la vinculación del legislador a los medios que debe adoptar para la realización de los derechos sociales, de acuerdo con los criterios de prohibición absoluta de inacción, establecer medidas inadecuadas e insuficientes o que impliquen "retroceso social" en estas materias resulta del todo inane, si no se consagra la potestad de la justicia constitucional para conocer de demandas

5 El denominado principio o cláusula de "prohibición de retroceso social" no ha sido contemplado en Colombia, ni por la ley ni por la jurisprudencia, lo que ha permitido la introducción de normas regresivas en materia social, como la reforma laboral de 2004, promovida por el actual Gobierno y que la Corte Constitucional, que ha venido girando hacia posiciones neo-liberales en los últimos tiempos, consideró constitucional. Otro ejemplo de regresión lo constituirían las reformas al régimen de transferencias de recursos del Gobierno central a las entidades territoriales y que han significado para éstas el recorte de fuentes de financiación en áreas tan sensibles para la realización de los derechos sociales, como la educación y la salud. por omisión legislativa de carácter absoluto; esto es, la inconstitucionalidad nacida de la renuencia del legislador a expedir las normas que la Constitución le ordena para regular ciertos asuntos, o en palabras de Carlos Gaviria Díaz, (sentencia C-543 de 1996): "todo incumplimiento por parte del legislador de su deber de acción expresamente señalado en la Constitución".

Como se sabe, este tema de gran complejidad no es posible abordarlo en los términos reducidos de esta ponencia. Baste decir que en Colombia no ha sido tratado institucionalmente, a diferencia de otros países de América Latina ${ }^{6}$. En reiteradas decisiones, la Corte Constitucional ha considerado que carece de competencia para conocer de demandas de inconstitucionalidad por omisión legislativa absoluta, si bien, a través de la figura de las "condiciones o circunstancias inconstitucionales" en casos específicos, como la situación de hacinamiento e insalubridad del sistema carcelario o en el de la población de cerca de 3 millones de desplazados por la violencia, ha buscado forzar al Gobierno para la adopción de medidas administrativas orientadas a superar tales condiciones de abierta contrariedad con los valores y principios de la Constitución.

6 En Brasil, en la Constitución de 1980 se consagró el mandato de "injunción", acción particular a través de la cual la omisión legislativa impugnada y que afecta la protección de derechos y libertades constitucionales es suplida por una orden judicial que produce efectos estrictamente "Inter partes".

En Argentina, al amparo de sus constituciones federales se ha ido desarrollando una jurisprudencia de precedentes a favor de la figura de la inconstitucionalidad por omisión.

En la Constitución Bolivariana de Venezuela de 2000, en el Art. 336, se atribuye al Tribunal Supremo de Justicia, en su sala constitucional, potestad para "declarar la inconstitucionalidad del poder legislativo municipal estatal o nacional, cuando haya dejado de dictar normas o medidas indispensables para garantizar el cumplimiento de la Constitución, o las haya dictado en forma incompleta y establecer el plazo y de ser necesario, los lineamientos de corrección". 


\section{LOS SISTEMAS INTERNACIONALES DE PROTECCIÓN DE LOS DERECHOS SOCIALES}

La tesis que se sostiene en este apartado es la siguiente: para los sistemas internacionales de protección de los Derechos Humanos, mundiales y regionales, el problema de la fundamentalidad o no de los Derechos Sociales y de su exigibilidad son asuntos relativamente superados, en la medida en que los distintos tratados y convenciones sobre la materia los definen como derechos inequívocamente fundamentalesy establecen, todavía tímidamente, algunos mecanismos de protección.

En la conferencia mundial de Derechos Humanos de 1993 promovida por las Naciones Unidas y que expidió la declaración y el Plan de Acción de Viena, se señala en la parte I, párrafo $5^{\circ}$ :

\begin{abstract}
Todos los derechos humanos son universales, indivisibles interdependientes y están relacionados entre sí. La comunidad internacional debe tratar los Derechos Humanos en forma global y de manera justa y equitativa, en pie de igualdad y dándoles el mismo peso [...] los Estados tienen el deber, sean cuales fueren sus sistemas políticos económicos y culturales, de promover y proteger todos los Derechos Humanos y las libertades fundamentales (las cursivas son mías).
\end{abstract}

En el caso del Sistema Europeo existen importantes avances, como el de la Reforma a la "Carta Social Europea" en el sentido de consagrar acciones individuales oponibles por parte de los sindicatos, asociaciones de trabajadores y organizaciones no gubernamentales. La mencionada reforma incorpora nuevos derechos sociales, como el derecho a la seguridad social para personas de la tercera edad, el derecho a la igualdad para los trabajadores casados, el derecho de protección contra la pobreza y la exclusión social y el derecho a la vivienda.

En el caso del sistema interamericano de protección a los Derechos Humanos, cabe destacar el protocolo de San Salvador, adicional a la convención americana sobre derechos económicos, sociales y culturales de 1969. En virtud de dicho protocolo -aprobado en 1988 y que entró en vigor en 1999- los derechos sociales son definidos como derechos fundamentales (Cepeda, 1992). Asimismo, se ha venido aplicando y enriqueciendo la jurisprudencia de la Corte Interamericana de Derechos Humanos, así como la producción doctrinaria de la Comisión de Derechos Humanos de la OEA, lo mismo que se han producido las primeras sentencias de aquella Corte condenando a varios Estados de la región por violaciones a los derechos sociales consagrados en la convención americana y en el protocolo adicional.

En cuanto a la producción doctrinal, vale la pena destacar cómo la Comisión Interamericana ha insistido en la integralidad, indisolubilidad e interdependencia de los Derechos Humanos. Ha sostenido la Comisión, por ejemplo:
La estrecha relación que existe entre la vigencia de los derechos económicos, sociales y culturales y la de los derechos civiles y políticos, por cuanto las diferen- tes categorías de derechos constituyen un todo indivisible que encuentra su base en el reconocimiento de la dig- nidad humana, por lo cual exigen una tutela y promoción permanentes con el objeto de lograr su vigencia plena, sin que jamás pueda justificarse la violación de unos en aras de la realización de otros (Fajardo, julio-septiembre de 2005).

Aunque el protocolo de San Salvador sólo permite reclamaciones individuales para los derechos a la Educación (Art. 13) y los derechos sindicales (Art. $\mathbf{8}^{\circ}$ ), la Comisión y la Corte Interamericana han aplicado el principio de conexidad para hacer valer otros derechos sociales a partir de un derecho civil o político, aplicando el criterio de integralidad de los Derechos Humanos. Al respecto, el expresidente de dicha Corte, Antonio Cançado Trindado, ha expresado:

Se impone el desarrollo de respuestas a nuevas demandas de protección, aunque 
no estén literalmente contempladas en los instrumentos internacionales de protección del ser humano vigentes. El problema sólo puede ser enfrentado adecuadamente teniendo en cuenta la indivisibilidad de todos los Derechos Humanos (civiles, políticos, económicos, sociales y culturales) (Fajardo, julio-septiembre de 2005).

En virtud del protocolo de San Salvador, la Corte Interamericana ha fallado varios casos protegiendo derechos sociales y económicos, obligando, por lo tanto, a los Estados a cumplir con sus obligaciones en esta materia ${ }^{7}$.

Aunque los casos de protección de derechos sociales por parte del sistema interamericano todavía son muy escasos, demuestran una tendencia cada vez más fuerte que, en contra de lo sostenido por Rodolfo Arango (1999) con respecto al carácter insustituible de los mecanismos internos constitucionales de protección, marcha en el sentido de su complementariedad con estos derechos.

\section{CONCLUSIONES}

Se ha señalado cómo, a partir del principio de necesidad $_{\iota}$ que responde mejor al carácter societario del derecho contemporáneo, es posible fundamentar los derechos sociales como derechos subjetivos; esto es, como posiciones jurídicas, capaces de generar derechos y obligaciones para el Estado o para terceros. Ahora bien, la positivización de estos derechos por vía constitucional les confiere el carácter de Derechos fundamentales, rompiendo así con la concepción de segmentación de los derechos, que considera como fundamentales solamente los derechos civiles y políticos.

7 Por ejemplo, caso Baena, Ricardo y otros contra el Estado de Panamá por violación al derecho de Asociación Sindical; condena al Estado de Honduras por no proporcionar medicamentos a cuatro ciudades hondureñas contra el VIH-SIDA. La Comisión Interamericana, con fundamento en esta sentencia, profirió medidas cautelares contra otros Estados (Guatemala, Nicaragua, El Salvador, Ecuador, Bolivia y República Dominicana) en circunstancias similares a las de Honduras, Caso No. 11.297, Juan Hernández contra Guatemala por violación al derecho a la salud; Caso 11.427 contra Ecuador protegiendo el mismo derecho.
En contra de tal segmentación, se pronuncian contemporáneamente las convenciones internacionales sobre Derechos Humanos de carácter universal y regional, así como las prácticas jurídicas de los tribunales internacionales de Derechos Humanos, que consideran a todos los derechos como indivisibles e interdependientes.

Con respecto a la exigibilidad interna de los Derechos Sociales, ésta cabe entenderla en dos niveles de concreción:

- Como reclamación individual, generalmente dirigida al Estado, en casos de urgencia extrema, en los cuales resulta seriamente comprometida la dignidad del ser humano.

- En la realización de las políticas públicas orientadas a la efectivización de los derechos sociales -las llamadas políticas sociales del Estado-, que en ocasiones cuentan con un marco directriz provisto por la Constitución, como ocurre en el caso colombiano, y que exigen la actuación del legislador y su operacionalización por parte de la Administración Pública a cargo del Ejecutivo. La actividad que se exige a los dos, legislativo y ejecutivo, deberá estar presidida por los principios de prohibición a la inacción, a medidas inadecuadas o insuficientes o a políticas que impliquen retroceso social.

La operancia de estos principios que obligan al Estado a realizar los derechos sociales a través de medios eficaces y que garantizan además la continuidad de tales medios, no será posible mientras que en los ordenamientos jurídicos no se establezca la inconstitucionalidad por omisión a cargo de los tribunales constitucionales, dotando adicionalmente a éstos, además, de mecanismos de incitación dirigidos al legislador y al ejecutivo, e incluso, de suplencia cuando éstos no actúan de conformidad con la Constitución. 


\section{REFERENCIAS}

Abramovich, V. \& Courtis, C. (2002). Los derechos sociales como derechos exigibles. Madrid: Editorial Trotta.

Arango, R. (Junio de 2001). La justiciabilidad de los derechos sociales fundamentales. Revista de Derecho Público, 12.

Arango, R. (1999). La protección nacional e internacional de los Derechos Humanos Sociales. Humbolt, Universidad de Berlín.

Arango, R. (2005). El concepto de Derechos Sociales Fundamentales. Bogotá: Editorial Legis.

Alexy, R. (1997). Teoría de los derechos fundamentales. Madrid: Centro de Estudios Constitucionales.

Bazan, V. (1996). Desafíos del control de Constitucionalidad. Buenos Aires: Ediciones, Ciudad Argentina.

Bazan, V. (2003). Respuestas normativas y jurisdiccionales frente a las omisiones inconstitucionales. En W.AA. En busca de normas ausentes. México: Universidad Autónoma de México.

Bernal, C. (2008). El derecho de los Derechos. Bogotá: Universidad Externado de Colombia.

Bobbio, N. (2008). El tiempo de los Derechos. Bogotá: Universidad Externado de Colombia.

Cançado, A. (Diciembre de 1998). La interdependencia de todos los Derechos Humanos. Revista Internacional de Ciencias Sociales, 151.

Cançado, A. (Diciembre de 1998). Obstáculos y desafíos en la implementación de los Derechos Humanos. Revista Internacional de Ciencias Sociales, 151.
Cepeda, M.J. (1992). Los derechos fundamentales en la Constitución de 1991. Bogotá: Editorial Temis.

Cotino, L. (2007). Derecho Constitucional II. LoS Derechos Fundamentales. Universitat de Valencia.

Ely, J.H. (1997). Democracia y desconfianza. Una teoría del control constitucional. Bogotá: Siglo del Hombre Editores, Universidad de los Andes.

Fajardo, L.A. (Julio-septiembre de 2005). La protección de los derechos sociales, económicos y culturales en el sistema interamericano de protección de los derechos humanos. Iusta, 23.

Gros, H. (1985) Interdependencia e indivisibilidad de los derechos humanos. En W.AA. Estudios de Derechos Humanos (tomo I). Madrid: Editorial Civitas.

Herreño, A.L. (2008) Todo o nada. El principio de integralidad y derechos sociales. Bogotá: Publicaciones ILSA.

Hart, H. (2004). El concepto de Derecho. Buenos Aires: Editorial Abeledo-Perrot.

López, C. (2005). Economía de Ios Derechos. Bogotá: Biblioteca Jurídica Dike.

López, D. (2006). El derecho de los jueces. Bogotá: Editorial Legis.

Nino, C.S. (1989). Ética y derechos humanos. Buenos Aires: Editorial Astrea.

Rawls, J. (1997). La teoría de la justicia. México: Fondo de Cultura Económica.

Salvioli, F. (Enero-junio de 2004). Protección de los derechos económicos, sociales y culturales en el sistema de protección interamericano de los Derechos Humanos. Revista del IIDH, 39. 
Sen, Amarthya. (2002). El derecho a no tener hambre. Estudios de Filosofía y Derecho, 3.
Uprimmy, R. (1982). Dialéctica de los Derechos Humanos en Colombia. Bogotá: Fondo de Publicaciones Universidad Autónoma de Colombia. 